\title{
Ranking of socio-cultural sustainability of tourism based on VIKOR model: Case study of tourism target villages of Noor city
}

\begin{abstract}
Sustainable development of rural tourism is based on a holistic approach to realization and continuance of development processes in the environmental dimensions of tourism target villages. Sustainable development can be achieved if the overlap is created between different dimensions. This means that each social system achieves a desirable level of sustainability to make it possible to judge sustainability. The community of tourism target villages has undergone extensive changes influenced by trends and policies of recent decades, but evidence shows that villages are moving towards unsuitability, and especially social unsuitability. The aim of the present study is to rank socio-cultural sustainability of tourism based on VIKOR model in tourism target villages of Noor city. It also aims to identify and design a network analysis process for determining the sustainable development of tourism, explain the links between elements and factors affecting sustainability using a descriptive-analytic methodology, and rank dimensions of rural tourism sustainability. The data were collected using library and field methods from 310 households that were selected as the research sample through Cochran formula. The results of the study showed that the protection of cultural patterns was ranked as the first sociocultural dimension $(\mathrm{R}=0.713, \mathrm{~S}=0.250, \& \mathrm{Q}=1)$, while awareness rising was ranked seventh $(\mathrm{Q}=0.000)$.
\end{abstract}

Volume 3 Issue I - 2019

\author{
Kazem Hassan Pour, ' Farshid Rostami, ${ }^{2}$ Vali \\ Ollah Rahmani ${ }^{3}$ \\ 'Department of Geography and Tourism Planning, Islamic Azad \\ University, Iran \\ ${ }^{2}$ Department of Geomorphology, Islamic Azad University, Iran \\ ${ }^{3}$ Department of Human Geography, Islamic Azad University, Iran
}

Correspondence: Kazem Hassan Pour, Department of Geography and Tourism Planning, Islamic Azad University, Noor Branch, Iran, Email kaemasapoor@gmail.com

Received: January 18, 2018 | Published: January 04, 2019

Keywords: rural tourism, socio-cultural sustainability, ranking sustainability level, target tourism villages

\section{Introduction}

Nowadays, given the interactive and communication capabilities, we see increasing the prosperity of rural tourism and the improvement of living standards and comprehensive development of villages. However, because of the lack of planning and management weaknesses, the opportunities available in villages in the field of tourism and the economic and social regeneration have been used excessively, while tourism-related threats and the lack of effective and sustainable planning in the villages in the region has been revealed. In the framework of optimal development approach for rural areas which is known as rural sustainable development, unlike the past, rural development is based on Clinger approach and a system that incorporates fundamental dimensions and forms the rural development system, and a balanced correlation between them. According to the definitions and concepts of sustainable development, the essential components of this development are economic progress, good governance, environmental quality, and social well-being. Meanwhile, as the Commission for Sustainable Development emphasizes, the dimensions of sustainable development include socioeconomic and environmental features that represent a balanced and interconnected concept in the form of a unified and interacting framework.

In the process of sustainable development, the role of social sustainability in realizing the goals of rural development is very important. The sustainability of the social system means improving the quality of life and the development of human resources and, ultimately, the self-empowerment of local communities to overcome internal challenges, respond to external changes, and the management of value preservation. In this sense, the social goals of sustainable development are underlined in the form of themes such as equal (intraand intergeneration opportunities, empowerment, improvement of quality of life, dignity and human rights, poverty eradication, cultural diversity, social solidarity, social participation, institutional capacity building, social security, accountability, social welfare and spatial attachment. According to the decrees of the Organization of Cultural Heritage, Handicrafts, and Tourism of Mazandaran Province in 2012, 37 villages of West Mazandaran have been selected as the tourism target village, of which 14 are located in the city of Noor. The city of Noor has an area of 2675 square kilometers, accounting for $11.11 \%$ of the province's total area. The city has 5 urban areas, 3 districts, 9 rural districts, and 182 villages with inhabitants in which the villages of Dizenca, Aghozqati, Khatib Kola, Sadat Mahaleh, Kayakla, Mollahmahaleh, Molakal, Beh Bonak, Kerchi, Reis Kala, Khortabl Rudbar, and Yush were selected as target villages, and villages of Yalrood and Jurband as the proposed target villages. According to 2011 National Census of Population and Housing, these villages have 1574 households and a population 5140 persons. The main rationale behind the selection of these villages was their high potentials for tourism attractions and the possibility of making planning for tourism development in tourism target villages. Therefore, with the rapid growth of tourism industry in the target tourism villages, the city of Noor must suffer from more pressure at least in the next decade. Currently, these villages face major socio-cultural problems in tourism development, which requires the assessment of sustainability of cultural and cultural factors in order to find solutions to the sustainable development and protection of target tourism villages in the city of Noor and provide conditions for improving the quality of services and raising the standards of living in these villages along 
with the preservation of cultural, historical, ad natural identity of the region, involving local people in making decisions, preparing them for life in a knowledge-based society, to achieve the goals of sustainable tourism target villages. Some of the common problems which can be seen in the region under study are the destruction of the environment, pollution and depletion of resources and tourism attractions that have led to the emergence of the current unfavorable and relatively unsustainable situation. This being so, the aim of this study is rank socio-cultural sustainability of tourism using VIKOR model in tourism target villages of Noor city.

\section{Literature review}

Sustainable development is the result of the fulfillment of environmental, social justice and economic goals. The World Tourism Organization first defined the concept of sustainable tourism in 1988 according to the criteria set in Brant Linden's Report, which defined as "satisfying the needs of present tourists and host communities by protecting and expanding opportunities for the future". ${ }^{2}$ Sustainable tourism development is also a particular form of tourism development that enables a system to survive a high level of quality. ${ }^{3}$ Sustainability means continuity in something like an activity and creation of a dynamic balance between the many effective factors such as natural, social, economic factors needed by human beings. ${ }^{4}$ The concept of sustainability has its root in an ecological principle. According to this principle, if in any environment, the resources are exploited proportionate to the natural production capacity of the environment, the original capital (ecological resources) remains stable and our use of the environment based on its production capacity always sustainable. Therefore, the amount of human use in that particular environment, which is in line with the power of the environment, results in the maximum yield. ${ }^{5}$ The concept of sustainability varies according to conditions such as the time and place of different societies, and thus there is no possibility of broadening and generalizing the concept of sustainability. ${ }^{6}$ Sustainability is increasingly a clear goal of developmental efforts, and remains as a widespread global concern, which is an inherently sophisticated debate. Providing precise and absolute definitions of this concept is impossible. ${ }^{7}$ The potential dimensions of sustainability, as in other dimensions of the human society, are of great importance. Different approaches to sustainable development indicators emphasize different aspects of sustainability ${ }^{9}$ Sustainable tourism development has three major economic, sociocultural, and environmental dimensions. Researchers suggest that sustainable development of tourism includes more dimensions than those described in the report of the Commission on the Environment and Development, as sustainable tourism is a combination of ecological, social, economic, political, institutional and technological dimensions at all international, national, regional, and local levels and as an interdisciplinary field which encompasses agricultural tourism, political science, economics, and ecology. These dimensions are interdependent and affect each other. ${ }^{9}$

\section{Social sustainability}

Social sustainability is defined as healthy and fertile life in harmony with nature. In this definition, the survival and life of the society is consistent with the preservation of environmental quality and related to the economic systems in order to achieve the highest level of life satisfaction. ${ }^{10}$ In defining social sustainability, a group of researchers have referred to four main and determinative elements: social justice, social solidarity, participation and security. In this sense, components such as equal opportunities for making progress for all people, life with cooperation, equal opportunities for all people to play their social roles along with the security of livelihoods and safety of human settlements against natural hazards are the basis for measuring social sustainability ${ }^{11}$ In addition, building the context for realization of creativity, the mobilization of people with emphasis on better future prosperity for all, meeting the goals of sustainable development , as well as the confidence in indigenous people and the emphasis on their vital role in environmental management and development, are among the main elements of the definition of social sustainability. ${ }^{12}$ In social sustainability, resources should be exploited in such a way that future generations will be able to make the best decision to meet their needs. In this definition, the win-win policy is emphasized by decision makers in order to achieve the economic, social, and environmental advancement. ${ }^{13}$ In a social approach to sustainable development, the condition of poor people and their basic needs are prioritized. In this approach, emphasis is placed on social justice. In this way, the material needs of people are among the priorities of sustainable development. There is no sustainability in societies in which justice does not exist, because such societies provide the context for a specific group to exploit other groups of the society. Therefore, the social dimension of sustainable development emphasizes the elimination of injustice and imbalance at the community level. In sustainable development with the social approach, the two concepts of participation and empowerment have a special place. ${ }^{14}$ Some scholars also believe that social sustainability involves equality, the provision of social services such as education and health, gender equality, political accountability and social participation. ${ }^{15}$ The concept of social sustainability is largely consistent with qualitative dimensions and is evaluated by concepts welfare and social capital. Social sustainability improves social capital by the formation of homogeneous and integrated societies with mutual interests and interactions among groups of people; societies with feelings of compassion, patience, and flexibility followed by love and loyalty and sometimes associated with moral capital. Social capital refers to the equal rights of human beings, religions and cultures, as well as the preservation of values that promote such conditions in human societies. ${ }^{16}$ Social sustainability in rural areas is defined as having a healthy living through fulfilling the basic needs of people and groups in the rural community by considering the quality of life and at the same time maintaining the quality of the environment and related to the economic systems in the path to achieving the highest level of life satisfaction. In this sense, social welfare and social stability cannot be sustainable without environmental health and economic mobility, so that it is through the interaction of the three dimensions of sustainability poverty reduction, social investment and a safe society arise from the social dimension. ${ }^{17}$ Sustainable social development, like the sustainable development of human society, has environmental, material, social, economic, legal, cultural, political and psychological aspects, all of which must be considered. Social sustainability in rural areas refers to living along with preserving the quality of the environment and is related to the economic systems to achieve the highest level of living. Achieving sustainable rural development depends on observing the three principles of regional balance, social justice, and political freedom. ${ }^{18}$ Social evaluation examines the social and cultural impacts of public and private activities on human societies. These activities change lifestyle, clashes and interactions, the organization of needs and eventually the participation of individuals and members of the community. Cultural influence includes changes in the norms, values, and beliefs of those that direct and rationalize their knowledge of themselves and their community. ${ }^{19}$ Various studies have been conducted on sustainability, some of which are reviewed here: 
Roknaddin in an article entitled "Tourism sustainability assessment in Iranian historical-cultural villages, focusing on the sustainable tourism development paradigm, examined tourism sustainability in terms of socioeconomic and environmental indicators in the historical cultural regions of Iran. in an article entitled "Determination of the severity of environmental instability of rural settlements using a multicriteria evaluation model" assessed the severity of environmental instability in 101 villages of 808 villages in Sistan and Baluchestan Province using a multi-criteria evaluation model in the Geographic Information System (GIS). The results of the study indicated that environmental instability in $18.8 \%$ of the villages is at a low or medium level, while it is severe or very severe in $81.2 \%$ of the villages. in an article entitled "Environmental impacts of coastal tourism projects in the Persian Gulf, evaluated sustainability and positive and negative effects of tourism on coastal tourism projects in the Persian Gulf. In another study, ${ }_{11}^{11}$ examined Tourism Outcomes in the instability of rural settlements in Baladeh Kojor District in Noshahr. In particular, they addressed the instability and the consequences of the presence of tourists in different dimensions in rural settlements. ${ }^{2}$ in an article entitled "Performance evaluation of coastal tourism complexes: Case Study of the Khazar Pearl Complex in Rasht" examined the available facilities and customer satisfaction of the complex. Studied the impact of tourism expansion on sustainable development dimensions in Hashtroud Town. in an article entitled "Rural development sustainability assessment: Case study of Komijan County, carried out an environmental, social and economic assessment of Komijan villages. Conducted a study on environmental sustainability assessment in five urban areas of Bandar-e Turkman using a linear multi-criteria decision-making technique. The main objective of their study was to assess and prioritize environmental sustainability in urban areas. The results for various steps of the linear distribution model in the form of zero and one planning showed that of the five urban regions of Bandar-e Turkman, District 5 was ranked as the first priority of environmental sustainability followed by districts 1,4 , 3 , and 2, respectively in a paper entitled "Sustainability evaluation in rural areas using the multivariate fuzzy topsis decision making technique", tried to identify several sustainability evaluation methods and choose one of these methods with an integrated approach. The aim of this study was to assess sustainability and rank the sustainability levels of the studied villages. The results of field studies indicated that the fuzzy topsis model, as a valuable and more effective method than multi-criteria decision-making techniques, can explain and rank the sustainability levels of rural areas in the study area.
In a study entitled "Measuring tourism sustainability from the perspective of local community in Niasar assessed the interests of local residents of Niasar city in the process of sustainable tourism? The results of the study showed that none of the interests of the host society due to the development of sustainable tourism in the city of Niasar has not been approved by the local community in terms of socio-cultural, economic, and environmental indicators, and only half of respondents believed that the interests of the host society in the implementation of sustainable tourism in Niasar has been considered, and realization of sustainable development in the form of community-based tourism requires cooperation of all economic sector to improve the quality of life of local communities and the natural environment. The tourism industry, as a subset of economic activities, should control its contribution to the sustainable development of tourism destinations. an article entitled "Socio-cultural sustainable development of tourism: Case study of Kish Island" examined the sustainability of the socio-cultural aspect of tourism development in Kish Island tourism destination. The results of the field survey and the research questionnaire indicated that the socio-cultural sustainability has not crystallized in the development of tourism in Kish Island.

\section{Materials and methods}

A systematic and holistic methodology was employed in this study, with emphasis on descriptive-analytical methodology and mixed methods including qualitative and quantitative survey. Given that the main objective of this study was to rank tourism sustainability level using VIKOR model in target tourism villages of the city of Noor, first the data were collected and classified in terms of socio-cultural dimensions. Afterwards, data coding was done based on the research variables. In order to perform data analysis, the collected data were processed SPSS and Expert Choice software packages and then they were organized through the VIKOR model and the sustainability levels of the regions under study were ranked. The research population included target tourism in city of Noor. The region under study included 14 villages and 1574 households, of which 310 household heads were selected as sample size using the Cochrane formula, as shown in Table $1 \&$ Figure 1:

$$
n=\frac{\frac{T^{2} p q}{d^{2}}}{1+\frac{1}{N}\left(\frac{T^{2} P q}{d^{2}}-1\right)}
$$

Table I Statistical population of target tourism villages in city of Noor

\begin{tabular}{lllllll}
\hline City & District & Rural district & Village & Household & $\%$ & Sample size \\
\hline Noor & Baladeh & Sheikh Fazlollah Noori & Yalrood & 40 & 2.54 & 8 \\
& & & Yush & 70 & 4.44 & 14 \\
& \multirow{3}{*}{ Chamestan } & Natal Rastagh & Jourband & 598 & 37.99 & 118 \\
& & Aghozqati & 5 & 0.31 & 1 \\
& \multirow{2}{*}{ Lavij } & Khatib Kala & 37 & 2.35 & 7 \\
& & Dizenkala & 162 & 10.29 & 32 \\
& & Sadat Mahaleh & 24 & 1.52 & 5 \\
& & Kayakla & 226 & 14.35 & 44 \\
& & Molla Mahaleh & 31 & 1.96 & 6 \\
& & Molla Kala & 60 & 3.81 & 12 \\
\hline
\end{tabular}




\begin{tabular}{|c|c|c|c|c|c|c|}
\hline City & District & Rural district & Village & Household & $\%$ & Sample size \\
\hline & & & Beh Bonak & 76 & 4.82 & 15 \\
\hline & & & Roodbar Khortab & 24 & 1.52 & 5 \\
\hline & & & Reis Kala & $|5|$ & 9.59 & 30 \\
\hline & & & Curchi & 70 & 4.44 & 13 \\
\hline Total & & & & 1574 & 100 & 310 \\
\hline
\end{tabular}

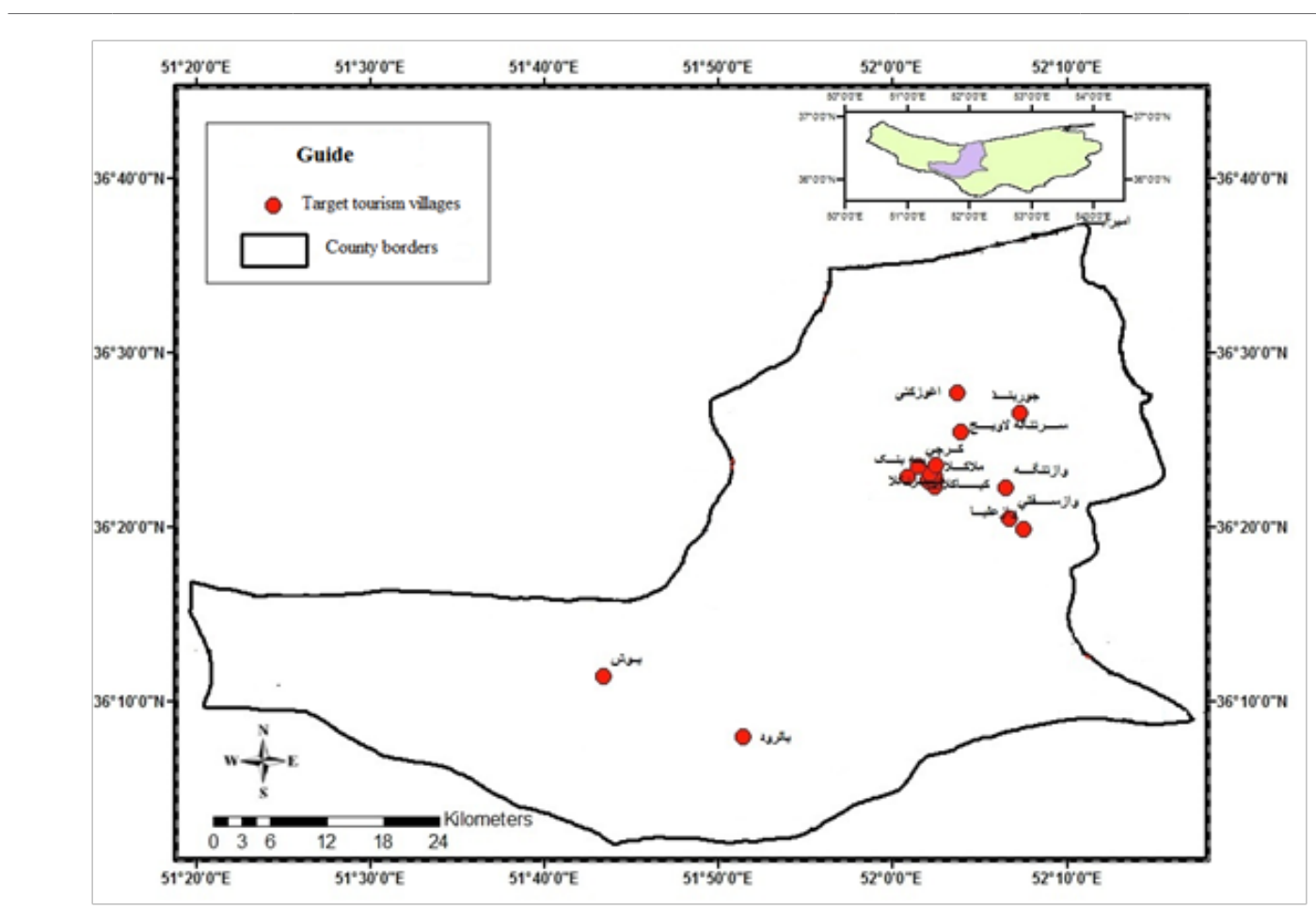

Figure I Target tourism villages in city of Noor.

\section{Results}

This section presents the results of data analysis:

\section{Ranking sociocultural sustainability levels of target tourism villages of city of Noor}

Table 2 shows the rankings of sustainability levels in terms of environmental dimensions and the position of tourism sustainability indicators in target tourism villages from the perspective of family heads and tourism experts:

\section{Ranking sociocultural dimensions}

In order to assess the sustainability of target tourism villages in the city of Noor in terms of socio-cultural dimensions, 5 components and 27 items have been used as the sustainability index. These components include culture and traditions (supporting and protecting cultural values and patterns, cultural conflict between tourists and the host community, protection and revival of customs and traditions of the local community, and creating the opportunity for cultural exchange between local people and tourists), raising the awareness of the local community (interaction between tourists and the host community, engaging tourists in protecting natural resources, participation of local residents in planning related to the tourism sector, increasing the participation of local residents in urban development, increasing the awareness of local managers about the needs and requirements of tourists, and increasing the awareness of local managers about the needs and requirements of tourists), satisfaction of the host community (satisfaction of the host society with the development of tourism, satisfaction of the host society with access to facilities and services in light of the presence of tourists, and the satisfaction of the host society with the presence and manner of the conduct of tourists), satisfaction of tourists (satisfaction of tourists with facilities provided, satisfaction of tourists with the tourism culture, satisfaction of tourists with the local community, and increasing the level of satisfaction of tourists with the destinations and places visited), development of facilities and services (expansion of welfare facilities for the host society, improving the quality of tourism-related services, enhancing recreational facilities and services, improvement of health facilities and services, improvement and development of communication networks, and improvement of sports facilities and services), protecting and supporting social patterns (the number of actions and programs undertaken to support and protect local values and patterns, the money spent on maintaining cultural and historical features, participation rate in traditional events, and the number of local tourist activities related to local culture), and social security and welfare (observing labor rights, observing women's rights, desecration for the local community due to the presence of tourists, and daily crimes and offenses). 
Table 2 The position of tourism sustainability indicators in target tourism villages

\begin{tabular}{|c|c|c|c|c|c|c|c|c|c|c|c|}
\hline \multirow[t]{3}{*}{ Components } & \multirow[t]{3}{*}{ Items } & \multicolumn{5}{|c|}{ Family heads } & \multicolumn{5}{|c|}{ Experts } \\
\hline & & \multicolumn{10}{|c|}{ I=Very High, 2=High, 3=Moderate, 4=Low, 5=Very Low } \\
\hline & & $\mathbf{I}$ & 2 & 3 & 4 & 5 & $\mathbf{I}$ & 2 & 3 & 4 & 5 \\
\hline \multirow[t]{5}{*}{ Culture and traditions } & Supporting and protecting cultural values and patterns & 43 & 39 & 118 & 68 & 42 & 4 & 8 & 6 & 6 & I \\
\hline & $\begin{array}{l}\text { Cultural conflict between tourists and the host } \\
\text { community }\end{array}$ & 49 & 82 & 128 & 32 & 19 & 6 & 6 & 8 & 2 & 2 \\
\hline & $\begin{array}{l}\text { Creating the opportunity for cultural exchange } \\
\text { between local people and tourists }\end{array}$ & 27 & 53 & 137 & 45 & 48 & 4 & 4 & 5 & 6 & 6 \\
\hline & Interaction between tourists and the host community & 22 & 43 & 106 & 74 & 65 & 4 & 5 & 4 & 6 & 6 \\
\hline & Engaging tourists in protecting natural resources & 31 & 34 & 118 & 71 & 54 & 8 & 4 & 6 & 5 & 2 \\
\hline \multirow[t]{4}{*}{$\begin{array}{l}\text { Raising the awareness of } \\
\text { the local community }\end{array}$} & $\begin{array}{l}\text { Participation of local residents in planning related to } \\
\text { the tourism sector }\end{array}$ & 13 & 24 & 89 & 95 & 89 & 6 & 5 & 6 & 6 & 2 \\
\hline & $\begin{array}{l}\text { Increasing the participation of local residents in urban } \\
\text { development }\end{array}$ & II & 24 & 95 & 84 & 96 & 4 & 6 & 6 & 5 & 4 \\
\hline & $\begin{array}{l}\text { Increasing the awareness of local managers about the } \\
\text { needs and requirements of tourists }\end{array}$ & 42 & 67 & 133 & 42 & 26 & 5 & 5 & 7 & 4 & 4 \\
\hline & $\begin{array}{l}\text { Increasing the awareness of local managers about the } \\
\text { needs and requirements of tourists }\end{array}$ & 31 & 42 & 128 & 68 & 41 & 4 & 8 & 4 & 5 & 4 \\
\hline \multirow[t]{5}{*}{$\begin{array}{l}\text { Host community } \\
\text { satisfaction }\end{array}$} & $\begin{array}{l}\text { Satisfaction of the host society with the development } \\
\text { of tourism }\end{array}$ & 54 & 67 & 127 & 35 & 27 & 6 & 6 & 7 & 2 & 4 \\
\hline & $\begin{array}{l}\text { Satisfaction of the host society with access to facilities } \\
\text { and services in light of the presence of tourists }\end{array}$ & 27 & 30 & 138 & 44 & 70 & 5 & 8 & 5 & 5 & 2 \\
\hline & $\begin{array}{l}\text { The satisfaction of the host society with the presence } \\
\text { and manner of the conduct of tourists }\end{array}$ & 46 & 49 & 96 & 77 & 42 & 3 & 5 & 5 & 6 & 6 \\
\hline & tourist satisfaction with facilities provided & 29 & 49 & 97 & 53 & 82 & 5 & 4 & 7 & 5 & 4 \\
\hline & tourist satisfaction with the tourism culture & 27 & 86 & 139 & 24 & 34 & 5 & 4 & 6 & 5 & 5 \\
\hline tourist satisfaction & $\begin{array}{l}\text { Increasing the level of satisfaction of tourists with the } \\
\text { destination and places visited }\end{array}$ & 32 & 52 & 96 & 79 & 51 & 6 & 5 & 5 & 5 & 4 \\
\hline \multirow[t]{8}{*}{$\begin{array}{l}\text { Development of facilities } \\
\text { and services }\end{array}$} & Expansion of welfare facilities for the host society & 32 & 37 & 54 & 90 & 97 & 6 & 7 & 8 & 2 & 2 \\
\hline & Improving the quality of tourism-related services & 26 & 52 & 111 & 72 & 49 & 6 & 8 & 7 & 3 & I \\
\hline & Enhancing recreational facilities and services & 24 & 26 & 86 & 73 & 56 & 7 & 8 & 5 & 3 & 2 \\
\hline & Improvement of health facilities and services & 29 & 29 & 96 & 89 & 67 & 7 & 7 & 7 & 2 & 2 \\
\hline & $\begin{array}{l}\text { Improvement and development of communication } \\
\text { networks }\end{array}$ & 39 & 45 & 129 & 54 & 43 & 8 & 7 & 5 & 3 & 2 \\
\hline & Improvement of sports facilities and services & 24 & 36 & 89 & 96 & 65 & 8 & 9 & 5 & 2 & I \\
\hline & $\begin{array}{l}\text { The number of actions and programs undertaken to } \\
\text { support and protect local values and patterns }\end{array}$ & 61 & 73 & 103 & 38 & 35 & 6 & 9 & 6 & 3 & I \\
\hline & $\begin{array}{l}\text { The money spent on maintaining cultural and historical } \\
\text { features }\end{array}$ & 46 & 47 & 97 & 45 & 75 & 5 & 7 & 6 & 4 & 3 \\
\hline \multirow[t]{2}{*}{$\begin{array}{l}\text { Protecting and supporting } \\
\text { social patterns }\end{array}$} & Participation rate in traditional events & 26 & 61 & 96 & 67 & 60 & 6 & 5 & 7 & 3 & 4 \\
\hline & $\begin{array}{l}\text { The number of local tourist activities related to local } \\
\text { culture }\end{array}$ & 42 & 61 & 114 & 44 & 49 & 9 & 9 & 10 & $\mathrm{I}$ & I \\
\hline \multirow[t]{4}{*}{$\begin{array}{l}\text { Social security and } \\
\text { welfare }\end{array}$} & Observing labor rights & 34 & 43 & 124 & 33 & 76 & 6 & 7 & 5 & 4 & 3 \\
\hline & Observing women's rights & 26 & 38 & 89 & 84 & 73 & 5 & 7 & II & $\mathrm{I}$ & I \\
\hline & $\begin{array}{l}\text { Desecration for the local community due to the } \\
\text { presence of tourists }\end{array}$ & 49 & 74 & 127 & 35 & 25 & 4 & 10 & 7 & 1 & I \\
\hline & Daily crimes and offenses & 62 & 76 & 124 & 25 & 23 & 4 & 9 & 5 & 4 & 3 \\
\hline
\end{tabular}




\section{Decision-making matrix}

Table 3 shows the formation of decision-making matrix for sociocultural dimensions of sustainability in the target tourism villages of the city of Noor:

Table 3 The formation of decision-making matrix for sociocultural dimensions of sustainability

\begin{tabular}{lllll}
\hline \multirow{2}{*}{ Dimensions } & Local people & Managers & Total & Distribution of results \\
\cline { 2 - 5 } & $\mathbf{0 . 3 5 4}$ & $\mathbf{0 . 3}$ & $\mathbf{0 . 3 4 8}$ & $\mathbf{0 . 3 3 3}$ \\
\hline Culture and traditions & 181.65 & 16.1 & 198.45 & 5 \\
Awareness raising & 164.96 & 15.06 & 177.76 & 4 \\
Host community satisfaction & 183.53 & 15.66 & 198.13 & 6 \\
tourist satisfaction & 172.05 & 15.25 & 189 & 4 \\
Development of facilities and services & 159.66 & 18.16 & 179.83 & 7 \\
Protecting social patterns & 184 & 17.65 & 201.68 & 5 \\
Social security and welfare & 186.1 & 16.95 & 203.05 & 5
\end{tabular}

Table 3 shows the formation of decision-making matrix for sociocultural dimensions of sustainability in the target tourism villages of the city of Noor:

\section{Normal matrix of sociocultural dimensions}

Table 4 shows the normal matrix that is formed by multiplying each number by itself and the sum of each column for sociocultural dimensions in the target tourism villages:

\section{Weighted normal matrix for sociocultural dimensions}

Table 5 shows the normal matrix formed by taking the square root of the sum of each column divided by the number for the decisionmaking matrix for sociocultural dimensions in the target tourism villages (Table 6, Table 7).

Table 4 Formation of the normal matrix for sociocultural dimensions

\begin{tabular}{lllll}
\hline \multirow{2}{*}{ Dimensions } & Local people & Managers & Total & Distribution of results \\
\cline { 2 - 5 } & $\mathbf{0 . 1 8}$ & $\mathbf{0 . 2 2}$ & $\mathbf{0 . 1}$ & $\mathbf{0 . 2 5}$ \\
\hline Culture and traditions & 32996.72 & 259.21 & 39382402 & 25 \\
Awareness raising & 27211.8 & 226.803 & 31598.62 & 16 \\
Host community satisfaction & 33683.26 & 245.235 & 39255.5 & 36 \\
tourist satisfaction & 29601.2 & 232.562 & 35721 & 16 \\
Development of facilities and services & 25491.315 & 329.785 & 32338.83 & 49 \\
Protecting social patterns & 33856 & 311,522 & 40674.82 & 25 \\
Social security and welfare & 34633.21 & 287.302 & 41229.3 & 25 \\
Total & 217473.5 & 1892.422 & 260200.5 & 192 \\
\hline
\end{tabular}

Table $\mathbf{5}$ The normal matrix formed by taking the square root of the sum of each column divided by the number for the decision-making matrix

\begin{tabular}{lllll}
\hline \multirow{2}{*}{ Dimensions } & Local people & Managers & Total & Distribution of results \\
\cline { 2 - 5 } & 0.18 & 0.22 & 0.1 & 0.25 \\
\hline Culture and traditions & 0.389 & 0.37 & 0.389 & 0.36 \\
Awareness raising & 0.353 & 0.346 & 0.348 & 0.288 \\
Host community satisfaction & 0.393 & 0.359 & 0.388 & 0.433 \\
tourist satisfaction & 0.368 & 0.35 & 0.37 & 0.288 \\
Development of facilities and services & 0.342 & 0.417 & 0.352 & 0.505 \\
Protecting social patterns & 0.394 & 0.40572 & 0.395 & 0.36 \\
Social security and welfare & 0.399 & 0.389 & 0.398 & 0.36 \\
\hline
\end{tabular}


Table 6 Weighted normal matrix for sociocultural dimensions

\begin{tabular}{lllll}
\hline \multirow{2}{*}{ Dimensions } & Local people & Managers & Total & Distribution of results \\
\cline { 2 - 5 } & $\mathbf{0 . 1 8}$ & $\mathbf{0 . 2 2}$ & $\mathbf{0 . 1}$ & $\mathbf{0 . 2 5}$ \\
\hline Culture and traditions & 0.07 & 0.081 & 0.038 & 0.09 \\
Awareness raising & 0.063 & 0.076 & 0.034 & 0.072 \\
Host community satisfaction & 0.07 & 0.079 & 0.038 & 0.108 \\
tourist satisfaction & 0.066 & 0.077 & 0.037 & 0.072 \\
Development of facilities and services & 0.0616 & 0.091 & 0.035 & 0.126 \\
Protecting social patterns & 0.071 & 0.089 & 0.039 & 0.09 \\
Social security and welfare & 0.0718 & 0.085 & 0.039 & 0.09 \\
\hline
\end{tabular}

Table 7 Determining the minimum and maximum number for each column and its difference in the sociocultural dimensions of target tourism villages

\begin{tabular}{lllll}
\hline & People & Managers & Total & Distribution of results \\
\hline$f \max$ & $0.07 \mathrm{I}$ & 0.091 & 0.039 & 0.126 \\
$\mathrm{f} \min$ & 0.061 & 0.076 & 0.034 & 0.072 \\
$\mathrm{f}+\mathrm{f}-\mathrm{F}-$ & 0.01 & 0.0157 & 0.004 & 0.054
\end{tabular}

Determining sociocultural utility index (S) and dissatisfaction index $(\mathbf{R})$

Table 8 shows the calculation the minimum and maximum number for each column and its difference minus the previous value of f-max for sociocultural dimensions from the respondents' perspective (Table 9):

\section{Calculating $Q$ value and final ranking of options in} terms of sociocultural dimensions

Table 10 shows the calculation of $\mathrm{Q}$ value and final ranking of options in terms of sociocultural dimensions (Figure 2, 3): Based on the calculations in which $\mathrm{S}$ is the distance between $\mathrm{i}$ and the ideal solution for the best combination and $\mathrm{R}$ as the distance from the ideal negative solution 0 is the worst combination. In the case that $\mathrm{V}>0.5$, the Qi index has maximum agreement and $\mathrm{V}<0.5$ means the equal group agreement. The results of the ranking indicate that protection of cultural patterns $(\mathrm{R}=0.713, \mathrm{~S}=0.250, \& \mathrm{Q}=1)$ occupies the first place of in terms of its contribution to sustainability, social security and welfare $\mathrm{Q}=0.969$ ) is ranked as the second most important factor, the development of facilities and services $(\mathrm{Q}=0.869)$ is ranked third, the satisfaction of the host community $(\mathrm{Q}=0.89)$ is ranked forth, culture and traditions $(\mathrm{Q}=0.858)$ is ranked fifth, tourist satisfaction $(\mathrm{Q}=0.108)$ is ranked sixth, and awareness raising $(\mathrm{Q}=0.000)$ is ranked seventh in terms of its contribution to sustainability of target tourism villages in the region under study. The results of the study also indicate that the position of sociocultural sustainability of the target tourism villages is undesirable in terms of awareness raising and tourist satisfaction as they were ranked at the lowest level of sustainability. In fact, the heads of families and tourism managers are expected to undermine sustainability in the area in question through unfavorable performance. In addition, the way tourism influences the local community, with a combination of positive and negative effects, is sustainable in terms of social security and welfare and the protection of cultural patterns. The functional nature of tourism shows that an unsustainable situation has been formed and the continuity of the current trend with the transition from a potentially unsustainable situation will end in unsustainability in a near future.

Table 8 The calculation the minimum and maximum number for each column and its difference minus the previous value of $\mathrm{f}$-max for sociocultural dimensions

\begin{tabular}{lllll}
\hline \multirow{2}{*}{ Dimensions } & Local people & Managers & Total & Distribution of results \\
\cline { 2 - 5 } & $\mathbf{0 . 1 8}$ & $\mathbf{0 . 2 2}$ & $\mathbf{0 . 1}$ & $\mathbf{0 . 2 5}$ \\
\hline Culture and traditions & 0.001 & 0.01 & 0.0009 & 0.036 \\
Awareness raising & 0.008 & 0.015 & 0.004 & 0.054 \\
Host community satisfaction & 0 & 0.012 & 0.0009 & 0.018 \\
tourist satisfaction & 0.005 & 0.0147 & 0.002 & 0.054 \\
Development of facilities and services & 0.01 & 0 & 0.004 & 0 \\
Protecting social patterns & 0.0008 & 0.002 & 0.0002 & 0.036 \\
Social security and welfare & 0 & 0.006 & 0 & 0.036
\end{tabular}


Table 9 Calculation of $Q$ value and final ranking of options in terms of sociocultural dimensions

\begin{tabular}{lllllll}
\hline Dimensions & Local people & Managers & \multicolumn{2}{l}{ Total } & \multicolumn{2}{l}{ Distribution of results } \\
\hline & 0.18 & 0.22 & 0.1 & 0.25 & $\mathrm{~S}$ & $\mathrm{R}$ \\
Culture and traditions & 0.03 & 0.146 & 0.018 & 0.166 & 0.361 & 0.166 \\
Awareness raising & 0.143 & 0.22 & 0.1 & 0.25 & 0.713 & 0.25 \\
Host community satisfaction & 0.017 & 0.177 & 0.019 & 0.083 & 0.297 & 0.177 \\
tourist satisfaction & 0.095 & 0.206 & 0.055 & 0.25 & 0.607 & 0.25 \\
Development of facilities and services & 0.18 & 0 & 0.091 & 0 & 0.271 & 0.18 \\
Protecting social patterns & 0.014 & 0.036 & 0.005 & 0.166 & 0.222 & 0.166 \\
Social security and welfare & 0 & 0.085 & 0 & 0.166 & 0.252 & 0.166 \\
& & $\mathrm{~S}-$ & 0.713 & 0.25 & -0.352 & -0.491 \\
& & $\mathrm{~S} *$ & 0.222 & 0.166 & & 0.717 \\
& & & & -0.083 & -0.083 & 0.717
\end{tabular}

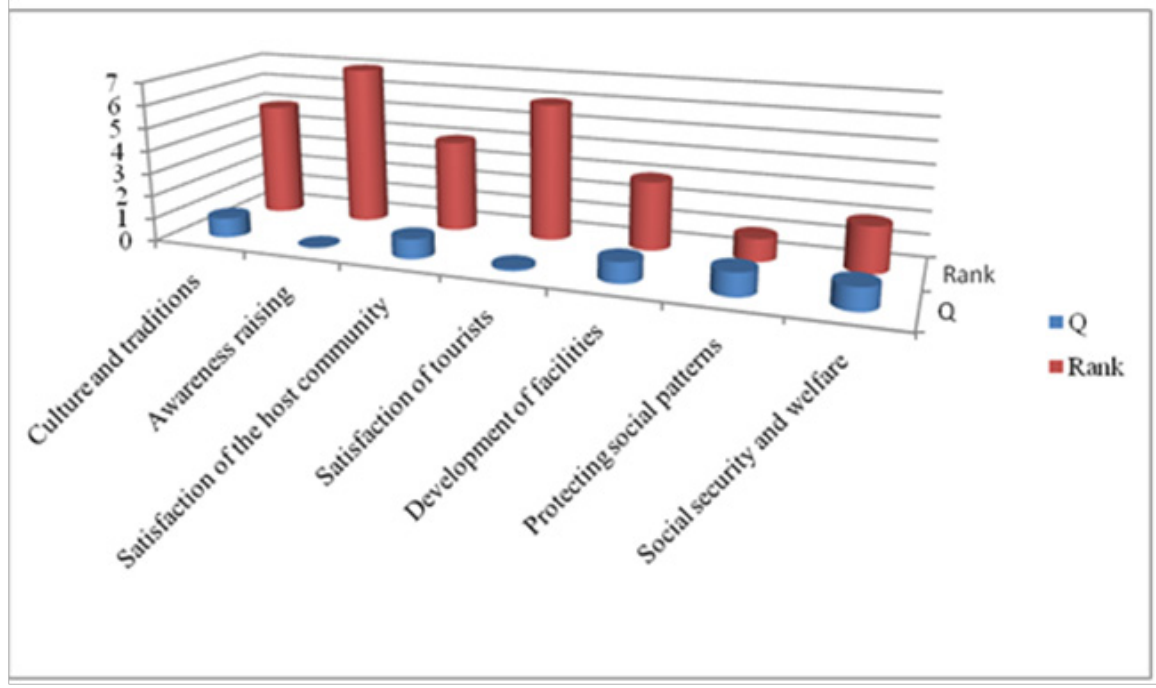

Figure 2 Calculation of $\mathrm{Q}$ value and final ranking of options in terms of sociocultural dimensions.

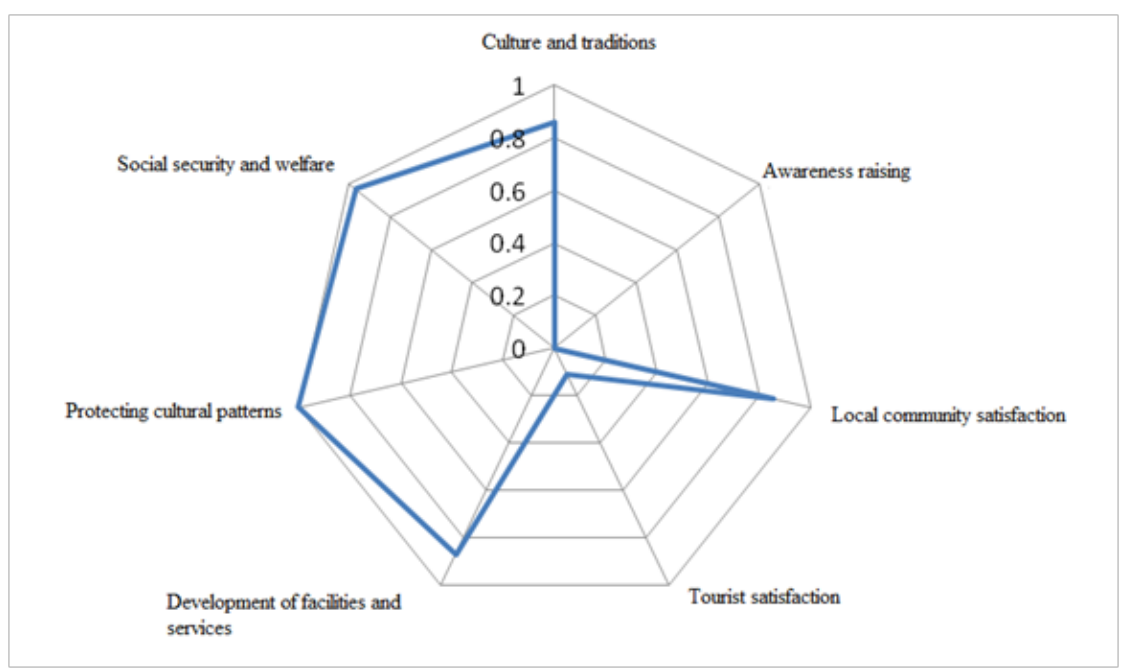

Figure 3 Sustainability of sociocultural components of tourism target villages.

Citation: Pour KH, Rostami F, Rahmani VO. Ranking of socio-cultural sustainability of tourism based on VIKOR model: Case study of tourism target villages of Noor city. Sociol Int J. 2019;3(I):30-39. DOI: 10.15406/sij.2019.03.00I50 
Table 10 Calculation of $Q$ value and final ranking of options in terms of sociocultural dimensions

\begin{tabular}{lll}
\hline Dimensions & $\mathbf{Q}$ & Rank \\
\hline Culture and traditions & 0.858 & 5 \\
Awareness raising & 0 & 7 \\
Host community satisfaction & 0.859 & 4 \\
tourist satisfaction & 0.108 & 6 \\
Development of facilities and services & 0.869 & 3 \\
Protecting social patterns & I & I \\
Social security and welfare & 0.969 & 2 \\
\hline
\end{tabular}

\section{Conclusion}

To overcome the challenges facing rural development on the eve of the third millennium, "the idea of sustainable development" is considered as the basis for rural development planning. Within the framework of this approach, rural communities and rural people are placed in a coherent and integrated manner with the land under their control, since the sustainability of the rural environment seeks to strike a balance between man, his environment, and his economic activities. In other words, sustainable development is the equilibrium point for the fulfillment of objectives of development in each of the environmental, social, and economic dimensions, which has, in the framework of past paradigms, led to a conflict between each dimension of development. However, in order to achieve sustainable rural development, according to the needs of rural communities, different weight, importance, and quantitative-qualitative aspects are considered different for its purposes, but a common ground can also be depicted. On the other hand, sustainability is not a concept that can be easily measured, because it's a non-constant quality, not a fixed point. It is easier to define this concept in practice, that is, there would be no forces that can disturb its balance over time. That is why most indicators actually measure volatility or the extent of imbalances. Since sustainability is a dynamic concept, it has different characteristics, such as the rate or extent of changes, the extent of the factors influencing its changes, and the amount and extent of changes that are related to the initial and final status. Therefore, in the present study, different groups with different goals, criteria, and options were used to assess sustainability the rural areas in target tourism villages of the city of Noor. In order to determine the sustainability of the target tourism villages, various indicators and criteria were employed and their sustainability levels were ranked in terms of three economic, social, and environmental aspects. Given the fact that sustainability criteria and indicators do not have equal value and importance and there is no specific threshold for determining their value and their exact importance, in this study, VIKOR model and the expert opinions were used to determine the final weight of ANP indices. By applying the obtained weight at the initial rate of indicators and criteria and integrating the weight indicators, the sustainability levels of target tourism villages in the city of Noor were determined. To this end, 5 components and 27 items were used as the sustainability indicators. The results of the rankings showed that the management and planning component was ranked first in terms of sustainability $(\mathrm{R}=0.333$, $\mathrm{S}=0.723, \& \mathrm{Q}=1)$, and the protection of natural heritage $(\mathrm{Q}=0.784)$, land resources $(\mathrm{Q}=0.78)$, production and management of materials $(\mathrm{Q}=0.499)$, bearing capacity $(\mathrm{Q}=0.403)$, pollution $(\mathrm{Q}=0.317)$, and conservation of biodiversity $(\mathrm{Q}=0.000)$ were ranked second to seventh, respectively, in terms of the sustainability of the target sample villages in the region under study. In fact, it is expected that the heads of families and tourism managers, through their functions, increase the sustainability in the area in question. This indicates a lack of attention to natural resources due to the lack of public awareness of these programs and projects and their future prospects, resulting in difference in opinions between people and officials. The following suggestions are offered based on the findings of this study:

a) Adopting community-based tourism development policies on the part of the public sector (Organization of Cultural Heritage, Handicrafts, and Tourism of Mazandaran Province) for active participation of the local community of city of Noor in terms of sustainable tourism development.

b) Social empowerment through the elimination of all forms of discrimination and inequality, in order to create a real context for people's participation in the process of regional development.

c) Improving the quality of services and raising the standard of living of people in target tourism villages, while preserving the cultural, historical, and natural identity of the region, increasing the presence of local people in decision making, preparing them for life in a knowledge-based society, and achieving the sustainability in targeted tourism villages.

d) Increasing tourism managers' commitment to provide required funds, encouraging investors in public and private sectors to make investments in target tourism villages and setting up units for sustainable rural tourism in order to monitor studies and accurate implementation of tourism projects, realization of goals, policies, and documentations of approved projects in the field of tourism with the high supervision of the Organization of Cultural Heritage, Handicrafts, and Tourism.

\section{Acknowledgments}

None.

\section{Conflicts of interest}

The author declares that there are no conflicts of interest.

\section{References}

1. Rural Development Planning Office Development of rural sustainable development indicators at national, regional and local level. UK: Sabzandish Payesh Consulting Engineers; 2007. 22 p.

2. George C. Impact Assessment Research Centre, Institute for Development Policy and Management (IDPM). University of Manchester; 2008.

3. Ko TG. Development of a Tourism Sustainability Assessment Procedure: a Conceptual Approach. Tourism Management. 2005;26(3):431-445.

4. Barrow CJ. Sustainable development, the concept of value and practice. Badri SA, editor. Geographical Research Quarterly. 19997;4(6):44-52.

5. Saraee MH, Mudeidfar S. Sustainability development in cities located in arid areas with emphasis on environmental components: Ardakan Town. Journal of Geography and Environmental Planning. 2010;21(1):47-76.

6. Mursouzi N, Bahrami R. Sustainable urban development. Iranian Statistics Center: Population and Housing Census. UK: Payam Noor University Press; 2011. 167 p.

7. Pretty JN. Participatory learning for sustainable agriculture. World Development. 1955;23(8):1247-1263. 
8. Muldan B, Bilyaz S. Sustainable development indicators. Tehrani NH Moharam Nejad N. EPA Publications. 2002. 22 p.

9. Rezvani MR, Akbarian Ronizi SR, Eftekhari al-Din A, et al. Explaining sustainability indicators in assessing the effects of tourism patterns in rural areas around metropolises: Case study of rural areas around the megacity of Tehran. Human Geography Research. 2012:81(1):35293652 .

10. GTZ. Chance for Sustainable Development, Program Office for Social and Ecological Standards. 2004. 60 p.

11. DFID. Indicators for Socially Sustainable Development. 2002.

12. Moffatt I. Sustainable Development, Principles, Analysis and Policies. London: The Parthenon publishing group; 1996. 206 p.

13. Martin. PJ. Speech delivered to the Conference on The European Social Agenda and the EU's International Partners. The Social Dimensions of Sustainable Development. 2009;1(2):221-255.

14. Overton J. Strategies for Sustainable Development. Newyork city: Zed books; 1999. $73 \mathrm{p}$.
15. Harris MJ. Basic Principles of Sustainable Development, Global Development and Environment institute. USA: Tufts University Medford MA 02155; 2000. 26 p.

16. Goodland R. Sustainability Human, Social, Economic and Environmental. USA: World Bank; 2003. 3 p.

17. Torjman Sh. The Social Dimension of Sustainable Development. UK: Caledon Institute Social Policy; 2000. 11 p.

18. Pourtaheri M, Ghidari HS, Sadeghloo T. Measuring and ranking social sustainability in rural areas using a ranking technique based on similarity to fuzzy ideal solution: Case study of the Suburban Rural District of the Central District of Khodabandeh). Rural Researches. 2009;8(2):235245

19. Vanclay B, Arkin L, Crenshaw R. Sustainable cities, environmental and social impact and strategies for eco city Development. Los Angeles: Ecohome media; $1995.10 \mathrm{p}$ 